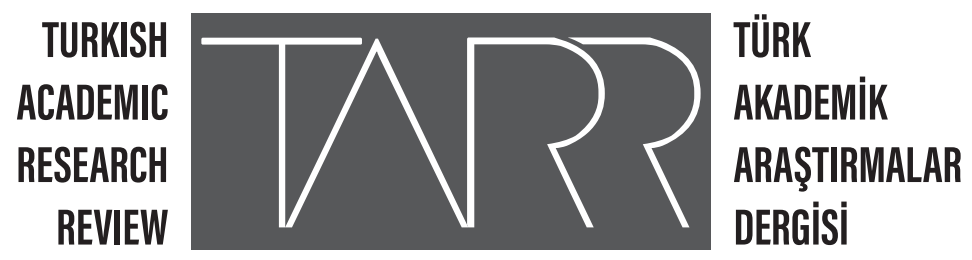

Iris Murdoch, Ateş ve Güneş, Platon Sanatçıları Niçin Dışladı?, çev. Serdar Rifat Kırkoğlu, Ayrıntı yayınları, İstanbul, 2008, ss.103. ISBN: 975-539-020-0

Irisi Murdoch, The Fire and The Sun, Why Plato Banished The Artists, Translator. Serdar Rifat Kırkoglu, Ayrinti Publish, İstanbul, 2008, ss. 103. ISBN: 975-539-020-0

\title{
Merve KESENCI
}

Doktorant, Akdeniz Üniversitesi Felsefe ve Din Bilimleri merve.bozan91@gmail.com

ORCID ID: 0000-0002-2939-6622

\author{
Makale Bilgisi | Article Information \\ Makale Türü-Article Type | Kitap İncelemesi / Book Review \\ Geliş Tarihi-Date Received | 20 Aralık/December 2019 \\ Kabul Tarihi-Date Accepted | 25 Mart / March 2020 \\ Yayın Tarihi-Date Published | 30 Mart/March 2020 \\ Yayın Sezonu | Ocak-Şubat-Mart \\ Pub Date Season | January-February- March
}

\begin{abstract}
Atıf/Cite as: Kesenci, Merve, Iris Murdoch, Ateş ve Güneş, Platon Sanatç1ları Niçin Dışladı?, çev. Serdar Rifat Kırkoğlu, Ayrınt1 yayınları, İstanbul, 2008, ss.103. ISBN: 975-539-020-0/ Irisi Murdoch, The Fire and The Sun, Why Plato Banished The Artists, Translator. Serdar Rifat Kurkoglu, Ayrinti Publish, İstanbul, 2008, ss. 103. ISBN: 975-539-020-0.tarr: Turkish Academic Research Review, 5 (1), 105-110. doi: tarr.662741

Intihal/Plagiarism: Bu makale, en az iki hakem tarafından incelenmiş ve intihal içermediği teyit edilmiştir. / This article has been reviewed by at least two referees and confirmed to include no plagiarism. https://dergipark.org.tr/tr/pub/tarr

Copyright (C) Published by Mehmet ŞAHIN Since 2016- Akdeniz University, Faculty of Theology, Antalya, 07058 Turkey. All rights reserved.
\end{abstract}




\section{Iris Murdoch, Ateș ve Güneș, Platon Sanatçıları Niçin Dıșladı?}

Çev. Serdar Rifat Kırkoğlu, Ayrıntı Yayınları, İstanbul, 2008, ss.103. ISBN: 975-539-020-0

\section{Irisi Murdoch, The Fire and The Sun, Why Plato Banished The Artists}

Translator. Serdar Rifat Kırkoglu, Ayrinti Publish, İstanbul, 2008, ss. 103. ISBN: 975-539-020-0

\section{Merve KESENCí ${ }^{1}$}

Iris Murdoch, felsefeci kimliğinin yanı sıra yazar ve şair olarak, felsefe ile edebiyatı birleştirmeyi önemsemiş bir düşünürdür. 1919 yılında İrlanda'da doğan Murdoch, yazmış olduğu 26 roman, 8 felsefe kitabı ve 8 tiyatro oyunu ile çağının üretken yazarlarındandır. Murdoch, bütün sanatçılar gibi kendisi de Platon'un sanatı ve sanatçı1 Devlet'inden kovma hususunda Platon'la hesaplaşmak istemektedir. Aslına bakılırsa bu hesaplaşmanın temelinde Platon'u daha iyi anlamak ve onun bizatihi sanatın kendisine değil, ahlakı saf dışı bırakan sanat eserlerine karşı bir tutum aldığını ortaya çıkarmak yatmaktadır.

Platon'nun sanatı ahlaki olarak bozulmaya sebep olabilir düşüncesiyle Devlet'inin dışında b1rakma görüşünü savunan Murdoch, ahlak felsefesinin göz ardı edilmesinin sonucu olarak, bozulan düşünce ve değerler sistemi ile bireyler arasında yok olan iletişimi görüyordu. Toplumun ahlak felsefesine gereksinimi olduğunu savunmuş ve bu alanda çalışmalar yapmıştı. Üretmiş olduğu eserlerini ahlak felsefesinin üzerine inşa ederek, bu felsefenin temelini oluşturan "iyilik" kavramı üzerinde durmuştu. ${ }^{2}$

Ateş ve Güneş kitabı sanat ve ahlak konusunda sürekli karşısında bulduğu Platon’u anlamak için ortaya çıkmış bir kitaptır. Kitap ilk olarak Oxford yayınları tarafından 1977'de basılmıştır. Türkiye'de ise 1992 ve 2008 olmak üzere Ayrıntı Yayınları tarafından iki baskısı yapılmıştır. İngilizce aslından Serdar Rifat Kırkoğlu tarafından Türkçeye çevrilmiştir. Kitap, "Platon aslında bütün sanatçıları dışlamadı.” Cümlesiyle başlayan Murdoch eseri, bir deneme tarzında bölümsüz ve başliksız olarak ele alınmıştır.

Murdoch kitabında, Platon'un özellikle Devlet eserinde sanatçıları dışlamasının sebeplerini, Platon'un diğer eserlerini de inceleyerek gerçekten bu dışlamanın temelinde neler yattığını ve Platon'un aslında bizatihi sanatın kendisine düşman olmadığını açığa çıkarmak istemiştir. Öyle ki kitabının daha ilk cümlesinde; "İlk ağızda şunu söyleyelim ki, elbette Platon bütün sanatçıları dışlamadı ya da herhangi birini dışlama fikrini her zaman ortaya atmadı”3 sözlerini dile getirerek kendi öngörüsünü ortaya koymuştur. Bu durum, Platon'un Devlet'inin yanlış anlaş1-

1 Doktorant, Akdeniz Üniversitesi Felsefe ve Din Bilimleri. merve.bozan91@gmail.com ORCİ: 0000-0002-2939-6622.

2 "Iris Murdoch", http://aykiriakademi.com/sanat/sanat-kitaplarin-dunyasi/iris-murdoch-felsefe-edebiyat, (erişim tarihi: 22.06.2019)

3 Iris Murdoch, Ateş ve Güneş, çev. S. Rıfat Kırkoğlu, Ayrıntı yay., İstanbul, 2008, s.9. 
dığını, Platon'un eleştirisi genelde sanatçı özelde ise şaire dair olduğunu göstermektedir. Temsili şiirin eğlenceden ibaret olduğunu bunun ise insana ahlaki anlamda bir şey katmayacağını bilakis ona kötü karakter kazandıracağını iddia eden Platon, temsili olmayan epik şiirlerin ise aksine yararlı olduğunu söyler. "Kitabının adından da anlaşılacağı üzere gölgelerle kaplı ateş ile gerçekliğin karanlık örtüsünü aralamamızı sağlayan güneşi karşılaştıran Murdoch, böylece aşkın olan iyi ideasına ulaşmada sanatın rolünü açığa çıkarmaya çalışır." Murdoch'un ateş ve güneş karşılaştırmasının Platon'un mağara alegorisine bir gönderme olduğu açıktır. Platon, insanların gördükleri şeylerin ateşin onlara yansımasından oluşan gölgelerden ibaret olduğunu, a sıl olanın ancak güneş 1şı̆̆ında görülebileceğini ve bunun için de mağaradan çıkmak gerektiğini söylemektedir. Murdoch da bu bağlamda güneşin 1ş1kları ile aydınlanmanın yani mağaradan çıkmanın sanat ile mümkün olacağını ifade etmiştir.

Murdoch kendisiyle yapılan edebiyat ve felsefe üzerine bir söyleşide de Platon'un sanatçılara olan bakış açısını şöyle özetlemiştir:

Platon sanata düşmanlığı konusunda adı çıkmış bir filozof. Bir siyaset kuramcısı olarak sanatların irrasyonel duygusal gücünden, onların çekici yalanlar, altüst edici hakikatler söylemesinden korkuyordu. Sıkı sansürü savunuyordu ve oyun yazarlarını ideal devletten kovmak istiyordu. Aynı zamanda kendi içindeki sanatçıdan da korkuyordu. Çok dindar bir adamdı ve sanatın felsefenin yanı sıra dine de düşman olduğunu düşünüyordu: Sanat dinin otoritesinin yerine geçebilecek bencil bir şeydi. Paradoks şu ki, Platon'un eseri kendisinin teorik olarak farkına varamayacağ1 anlamda büyük sanat. Felsefe ve şiir arasında eski bir tartı̧̧ma olduğunu söyler Platon; o halde Platon'un zamanında bildiğimiz anlamda felsefenin her tür şiirsel ve teolojik spekülasyondan yeni yeni ayrılmaya başladığını hatırlamamız gerekir. Felsefe kendini başka bir şey üstünden tanımlamadan ilerleme kat eder. Felsefe, Platon'un zamanında kendini edebiyattan ayırd1, 17. ve 18. yüzyılda doğa bilimlerinden, yirminci yüzyılda da psikolojiden. Platon sanatın mimesis olduğunu düşünüyordu, yalnız kötü mimesis olduğunu düşünüyordu. Zira her zaman etrafta iyi sanattan çok kötü sanat olduğu ve kötü sanat seven insanların iyi sanat sevenlerden çok olduğu gerçek. Platon sanatın özünde kişisel bir fantezi, değersiz şeylerin yüceltilmesi ya da iyi şeylerin çarpıtılması olduğuna inanıyordu. Genel önemi olmayan özel nesnelerin gereksiz yere kopyalanması olarak görüyordu sanatı, kuşkusuz sanatın büyük bir kısmı böyle. Platon'un televizyon hakkında ne düşüneceğini bir hayal edin. Ona göre insanlar gerçek dünyaya bakmalı ve onun üstüne düşünmeli, önemsiz imgelerden ve nahoş hayallerden tatmin olmamalı. ${ }^{6}$

Murdoch, Platon'un sanata değil kötü sanata karşı olduğunu ancak her ikisinin de taklit olduğu için her zaman gerçekten daha aşağıda olduğunu düşündüğünü dile getirmektedir. Platon; “in-

4 R. G. Collingwood, The Prenciples of Art, Oxford Press, New York, 1958, s. 47.

5 Fatma Dore, “Devlet’teki Bir Yasağa İtiraz: Iris Murdoch ve Platon’un Sanatçı Görüşüne İtirazı”, Afyon Kocatepe Üniversitesi, Sosyal Bilimler Dergisi, Cilt: XIV, Say1 2, 2012, s.67.

6 "Iris Murdoch" https://oggito.com/icerikler/iris-murdoch-felsefe-tek-bir-sey-yapar-edebiyat-pek-cok-sey-/5382, (erişim tarihi: 22.06.2019). 
sanlara bir meşe ağacını dinlemek yeterdi...” derken de Murdoch’un gerçek dünyaya bakmak tabiri açıklığa kavuşmuş oluyordu.

Murdoch kitabı yazmasının sebebini açıklarken, Platon'un Devlet'te sanatçıları neden ahlaki anlamda zayıf kişiler olarak işlediğini merak ettiğini ve diğer diyaloglarından bu tutumun derinliğine inerek sanata dair incelikler bulmayı ve Platon'un haklı olup olmadığını görmek istediğini dile getirmektedir. Murdoch'un Platon'da bir açık kapı aramasının en büyük sebebinin onu okurken bir felsefeci olarak değil de bir yazar olarak, yani bir sanatçı olarak okumasında yatmaktadır diye düşünmekteyiz. "Platon sanatı bütün tehlikelerine rağmen önemsiz olarak görseydi onu dışlarken bu kadar duraksamazdı"7 demesi de Platon'daki kapıları aralamanın ilk göstergesi olarak dikkati çekmektedir.

Platon'un mitolojik betimlemesi olan "Mağara Alegorisi”, Murdoch için yanılgıdan gerçeğe doğru ruhsal yükselişin en iyi açıklanış biçimidir. Ona göre bu mitos, aşamalı kavrayışla ulaşılan ahlaklı yaşam için bir metafor, ruhsal bir tür kilavuzdur. ${ }^{8}$

Ahlak ve iyi Platon için vazgeçilmez iki şeydir. Dolayısıyla sanat da estetik olduğu sürece ruha iyi gelecek onu tedavi edecektir. Platon'un ilgilendiği şey daha doğrusu dişladığı şey sanat tüketiminin sonuçlarına dayalı olduğu için olumsuz olarak alınmaktadır. ${ }^{9}$ Bu bağlamda Platon'un yalnızca sanatı değil dünyanın zevklerini de şiddetle reddettiği görülmektedir: "İnsan büyük bir şey değildir, bizler birer gölgeyiz, vücut bir süprüntüdür..."10

Platon'un sanat dallarına karşı olan söylemlerine değinen Murdoch, Platon'un tiyatroya büyük bir bayağılık yuvası, kaba davranışların sergilendiği yer, zamanında Sokrates’e yöneltilen iftiralar dolu bir yer olarak gördüğünü kaydetmektedir. ${ }^{11}$ Müziğe sıra geldiğinde ise Murdoch, müziğin simgesel rolünü Platon'un kabul ettiğini ancak belki de sınırsız güçlerinden korktuğu için matematiğin bir dalı olarak kabul etmekle kalmış ve yükselmesine müsaade etmemiştir. ${ }^{12}$ Şiire ise sadece didaktik (Tanrılara ilahiler ve iyi insanlara düzülen methiyeler) olarak Devlet'inde izin verdiğini dile getiren Murdoch, en çok yazı konusunda Platon'un karşı durduğunu da ifade etmiştir. Platon için, bilen ve bilmeyen arasına bir aracı soktuğunu söylemiş ve diyaloglardan örnek vermiştir: "Yazı şimdiki zamanda bulunan hakikatle doğrudan ilişkiyi bozar... o yüzden yazı insan için tam da bir hakikatten ve gerçeklikten uzak durma yoludur." ${ }^{3}$ Platon, kurtulmak isteyenin yazı ve tiyatro yerine yıldızlara bakmasını önermiştir.

Murdoch, kitabın ilerleyen safhasında Platon'un güzellik algısına karşı olan tutumunu inceler ve onun güzelliğe sanattan farklı olarak değer verdiğini ifade eder. Çünkü Platon’a göre güzel,

7 Murdoch, Ateş ve Güneș, s.10.

8 Fatma Dore, “Devlet’teki Bir Yasağa İtiraz: Irıs Murdoch Ve Platon’un Sanatçı Görüşüne İtirazı”, Sosyal Bilimler Dergisi / Cilt: XIV, Sayl 2, 2012, s. 63.

9 Murdoch, Ateş ve Güneş, s.21.

10 Murdoch, Ateş ve Güneş, s.22.

11 Murdoch, Ateş ve Güneş, s.22.

12 Murdoch, Ateş ve Güneş, s.25.

13 Murdoch, Ateş ve Güneş, s.31. 
yan Eros, Tanrı ve insan arasındaki bağı kuran şeylerin sevgisidir aynı zamanda. "Güzellik sanatçılara bırakılmayacak derecede önemli bir meseledir; sanat güzelliğe ancak söz gelimi matematiksel model düzeyinde, yani denetlenebilir ve basit bir düzeyde karışabilir. Doğa bizi eğitir, sanatsa eğitmez."14 Platon'a göre güzellik Tanrı'da aranmalıdır çünkü güzellik bizatihi Tanrı'nın kendisidir. Evren ile güzelliği ortaya çıkaran da O'dur ve evren gerçek estetik olan tek nesnedir. Dolayısıyla doğaya dönerek estetik ve güzeli bulmalı ve sanattan da yalnızca bu ölçüde yararlanmalıyız. ${ }^{15}$

Murdoch Platon'un sanata karşı, sanatın tinsel olanı taklit etmesi ve onu önemsizleştirmesinin, böylece sanatın, önemsiz ve yavan şeylerin çoğalmasına sebep olduğunu söylemektedir. Dolayısıyla soytarılık yoluyla iyi ve kötüyü ayırt etmeyi gölgelediğini ve sanatçının şeytani ve aşırı olanı temsil ettiğinden dolayı sanatı tehlikeli bulduğunu ifade etmektedir. Oysa Platon'a göre gerçek sessiz ve ağırbaşlıdır. ${ }^{16}$

Platon'un argümanlarını yeterince ortaya koyduğunu düşünen Murdoch, kitabının sonuna doğru, ona itirazlarını dile getirmiştir. Murdoch'a göre; sembolik olarak düşünülen iyi sanat, insana daha yüksek iyiyi sunar, dua ya da dinin bulunmadığı yerde ona deneyim sağlar. Ac1lardan bir şeyler öğrenmemizi sağlayan sanat, hepimizin buluşabileceği ve güneş altında gerçekleri gözden geçireceği bir salondur. Bu yüzden Platon gibi otorite yanlıları ondan korkarlar. Sanatçı ise, Murdoch'a göre en kötüsünden bir dedikoducu en iyisinden bir bilgedir ve her iki halde de sevilebilir. ${ }^{17}$

Kötü sanatın neden ve nasıl zararlı olabileceğinin pek kolay yanıtlanamayacak bir soru olduğunu ifade eden Murdoch, büyük sanatın ise hiç şüphesiz iyinin yönünü gösterdiğini dile getirir. Ahlakçı için büyük sanatın bir yardımcı değerinin bir düşman olarak değerinden daha fazla olduğunu savunan Murdoch’un, Ateş ve Güneş’i şu cümlelerle sona ermektedir:

Sanat aracılık edecek ve süsleyecek ve Tanrı'nın yokluğunu ya da uzaklığını gizlemek için büyülü yapılar geliştirecektir. Bu türden pek çok yapının çökmekte olduğu bir zamanda yaşıyoruz ve Batı'da din ve metafizik sanatın kendilerinden açtığ kucaktan uzaklaştıkça aklı tatmin edecek imgelerden yoksun kalan bizler, birer mistik olmaya zorlanıyormuşuz gibi görünebiliyoruz. Sofistik ve büyü arada sırada bir çöküntü yaşar ama hiçbir zaman ortadan kaybolmaz. Sanatla aralarındaki gizli anlaşmalarının ve sağlayabildikleri avuntuların sonu yoktur. Ve sanat, tıpkı yazı gibi, Eros gibi, iyi de olsa, kötü de olsa var olmayı sürdürür. ${ }^{18}$

Platon için objektif değerlendirmelerde bulunan bu kitapta Murdoch, sanatı kötü de olsa desteklemesiyle Platon'dan ayrılır. Platon'un Devlet'inde kötü her ne olursa olsun kişinin ahlakını zedeleyecek bir şeydir. Taklit de olsa oradaki kötü karakterlere, izleyenlerin özenebilme ve benzeyebilme ihtimalinin dahi önüne geçmek istemiştir. Oysa Murdoch kötü sanatı zararsız görür.

14 Murdoch, Ateş ve Güneş, s.52

15 Murdoch, Ateş ve Güneş, s.62.

16 Murdoch, Ateş ve Güneş, s.75.

17 Murdoch, Ateş ve Güneş, ss. 86-96.

18 Murdoch, Ateş ve Güneş, s.98. 
Kitap, bitmez bir tartışma olan Platon'un sanatçıları Devlet’inden dışlaması üzerine yazılmış, Platon'un düşüncelerinin incelenişi ve sanatın iyi ve kötü olarak ne ifade ettiğini, kötü olan sanatı gerçekten kovmak gerekip gerekmediği sorularına yanıt arama açısından aydınlatıcı bir çalışmadır.

Murdoch, her ne kadar kendisini ahlaki olarak sanatı ele alıs tarzları bakımından Platon ile aynı minvalde görse de, Platon'un sanata karşı duruşunu eleştirmektedir. Çünkü Platon bir filozof, Murdoch ise daha çok bir sanatçıdır. Bu nedenle kötü dahi olsa sanatın varlığını sürdürmesi gerektiğini savunur. Platon ise insanların iyi kalmasının iyiyi örnek almaktan geçtiğini bunun da ancak iyinin taklit edilmesiyle mümkün olduğunu dolayısıyla sanatın yalnızca iyiyi taklit etmesi gerektiğini iddia etmektedir.

Platon'un bir filozof olarak Devlet'ini kurarken kötü şeyleri kapının dışında bırakmasına hak verileceği gibi, Murdoc'un da bir sanatçı olarak sanatın her halini savunması da anlayışla karşılanmalıdır.

\section{Kaynakça}

"Iris Murdoch" https://oggito.com/icerikler/iris-murdoch-felsefe-tek-bir-sey-yapar-edebiyat-pek-coksey-/5382, (erişim tarihi: 22.06.2019).

"Iris Murdoch", http://aykiriakademi.com/sanat/sanat-kitaplarin-dunyasi/iris-murdoch-felsefeedebiyat, (erişim tarihi: 22.06.2019)

Collingwood, R. G., The Prenciples of Art, Oxford Press, New York, 1958.

Dore, Fatma, “Devlet’teki Bir Yasağa İtiraz: Iris Murdoch ve Platon’un Sanatçı Görüşüne İtirazı”, Afyon Koca Tepe Üni, Sosyal Bilimler Dergisi / Cilt: XIV, Say1 2, 2012.

Murdoch , Iris, Atę̧ ve Günȩs, çev. S. Rıfat Kırkoğlu, Ayrıntı yay., İstanbul, 2008. 